\title{
Somatic Symptoms in Young Adult Women Who Experienced Sexual Violence Throughout Life Development: A Systematic Review
}

\author{
Angelia Nathali Pichel ${ }^{1}$ Denrich Suryadi ${ }^{1 *}$ \\ ${ }^{1}$ Faculty of Psychology, Universitas Tarumanagara, West Jakarta, Special Region of Jakarta 11440, Indonesia \\ "Corresponding author. Email: denrichs@fpsi.untar.ac.id
}

\begin{abstract}
Sexual violence is a public health problem that occurs worldwide with women being the majority of victims. Gray et al. (2004) explained that sexual violence and unwanted sexual experiences are included as one of traumatic life events (TLE). TLE has various impacts on the mental health of individuals. One of the effects that can arise is somatic symptoms. Research over the course of years has shown that somatic symptoms often appear in women victims of sexual violence, both childhood sexual abuse (CSA) and also adolescent/adulthood sexual assault (ASA). However, there are still few systematic review researches that discuss the appearance of somatic symptoms and psychological conditions that exist in women victims of sexual violence. This study aims to analyze various research results that show the psychological impact and somatic symptoms on women victims of sexual violence and also the relationship or mediator of the two variables. This systematic review uses 3 research databases; ScienceDirect, PubMed, and Taylor and Francis Online with researches time span from January 1, 2015 to December 31, 2020. The total research used after screening was 8 studies from 4 different countries. The results of this systematic review showed that women victims of sexual violence who experienced somatic symptoms reported having previous psychological conditions such as depression, PTSD, dissociation, and anxiety. These psychological conditions can be a mediator, cause, or predictor of somatic symptoms. Conversely, somatic symptoms that appeared can also be an indicator of psychological disorders on victims.
\end{abstract}

Keywords: Women victims of sexual violence, trauma, somatic symptoms

\section{INTRODUCTION}

Sexual violence is one of the major public health problems $[5,45]$. Sexual violence can happen to anyone, anywhere and anytime. The World Health Organization or WHO [13] defined sexual violence as any form of sexual acts, attempts to commit sexual acts, sexual comments and advances, or acts of coercive sexual exploitation of the sexuality of others, regardless of the relationship between the perpetrator and the victim, in all situations, not limited to residence or workplace. In Indonesia, based on the 2019 Record of Violence Against Women (CATAHU 2020) by the National Commission on Violence Against Women (Komnas Perempuan), the number of cases of violence against women continues to increase every year with the number of physical and sexual violence cases in the personal sphere being the highest for 5 consecutive years. In addition to violence against women in the personal sphere, Komnas Perempuan also categorizes violence against women in the public or community sphere. The number of cases of sexual violence against women in the public sphere is the highest compared to other forms of violence. The data shows 715 cases of rape, 551 cases of sexual abuse, and 520 cases of sexual harassment [23]. CATAHU 2020 noted that most victims and perpetrators are in the age range of 25 to 40 years, who are young and productive adults.
Previous studies have reported several psychopathological effects on female sexual violence victims, some of which are depression $[1-2,8,10,20,44]$, anxiety [2, 8], PostTraumatic Stress Disorder or PTSD [1-2 , 4, 5, 24, 38], and somatic symptoms [4, 6, 26, 37, 42, 45].

Trauma experienced by female sexual harassment victims has the same trauma impact as other stressful life events such as being dismissed from work, breaking up, suffering from serious illnesses, and death of a close relative [28]. Research by Gibson et al. [14] regarding the impact of traumatic life events (TLE) using 17-item Life Events [17] indicated that TLE is significantly associated with the emergence of psychological disorders such as PTSD, Borderline Personality Disorder (BPD), and Attenuated Positive Psychotic Symptoms (APPS). The 17-item Life Events by Gray et al. [17] contains 17 forms of TLE, two of which are related to sexual violence, namely sexual assault and unwanted sexual experiences.

Studies from past years that have been listed previously also reported consistent results, namely the presence of psychological disorders such as anxiety, depression, PTSD, to somatic symptoms in victims of sexual violence. In several studies, the subjects studied were young adult women who had experienced childhood sexual abuse (CSA). With the large number of female sexual violence victim in Indonesia who are currently young adults, this research is necessary to explore deeper the psychological impact and 
manifestations of somatic symptoms in young adult female victims. Study by Ciocca et al. [11] stated that women who have experienced sexual violence are much more susceptible to physical complaints or somatic symptoms, pain disorder, vaginismus, and sexual dysfunction. According to researchers, the psychological impact and the manifestation of somatic symptoms can affect and disrupt the life and social function of the victim $[26,36]$. Based on the above phenomena and explanations, the researcher wants to know how psychological disorders can cause somatic symptoms and the types and varieties of female sexual violence victims aged 20 to 40 years.

\subsection{Variable Definition}

The following is an explanation of somatic symptoms, young adult women, and sexual violence

\subsubsection{Somatic Symptom Disorder (SSD)}

At the beginning of the development of psychology, somatic disorders experienced by individuals were associated or referred to as hysteria by Janet [19] and Freud [7]. More deeply, Breuer \& Freud [7] explained that hysteria arises due to individual traumatic experiences, in this case specifically sexual trauma. As the science of psychology develops, the core characteristics of hysteria are classified into independent categories, namely dissociative disorders and somatic disorders. According to the Diagnostic and Statistical Manual of Mental Disorder Fifth Edition (DSM-V), somatic symptom disorder or what is often referred to as somatic symptom disorder (SSD) is one or more somatic symptoms that arise and cause difficulties for individuals or cause significant disruption in the individual's life everyday.

\subsubsection{Other Somatic Symptoms Classifications}

During the development of psychology, there were several concepts of somatic symptoms that developed side by side with SSD, including functional somatic symptoms (FSS). According to Roennerberg et al. [35] FSS refers to a large spectrum of somatic symptoms of varying severity that meet the criteria for somatoform disorders and SSD. It is further explained that the FSS interferes with individual daily activities so that individuals seek medical help. However, the symptoms one feels cannot be explained medically and do not meet the criteria for a particular disease.

\subsubsection{Young Adult Women}

Papalia and Martorell [33] in the book Experience Human Development defined young adults as individuals aged 20 to 40 years. Thus, a young adult woman is any woman who is between the ages of 20 and 40. In his theory of psychosocial development, Erikson categorizes young adults in the age range of 20 years to the end of 30 years of age. According to Erikson [12] for young adults, the stage of psychosocial development is intimacy vs isolation. The characteristic of this stage of development is that the individual tries to build an intimate relationship with a partner. Furthermore, Papalia and Martorell also explained that in the young adult age range, individuals become sexually active. This could explain why the majority of victims and perpetrators of sexual violence in Indonesia are in the young adult age range. Through extensive research, female young adults are more susceptible to psychological disorders such as depression (MDD) or other psychological disorders [21, 25, 33]. This is the reason this study chose young adult women as the main subject.

\subsubsection{Sexual Violences}

Sexual violence is one of the major public health problems $[5,45]$. The World Health Organization or WHO [13] defined sexual violence as any form of sexual acts, attempts to commit sexual acts, sexual comments and advances, or acts of coercive sexual exploitation of the sexuality of others, regardless of the relationship between the perpetrator and the victim, in all situations, not limited to residence or workplace. The key to the overall definition of sexual violence is the element of coercion or coercive action [43]. Sexual violence is a large umbrella for various sexual acts against the wishes of the victim, ranging from contactless acts such as exhibitionism to rape which causes various physical and emotional impacts [4]. Luce, Scharger, and Gilchrist [27] stated forms of sexual violence, namely violence by partners, human trafficking, forced prostitution, sexual slavery, sexual exploitation, neglect, child murder and sexual abuse.

\subsection{Our Contribution}

Theoretically, this study can provide an overview of the types of somatic symptoms that arise in female sexual violence victims aged 20 to 40 years and their relationship to psychological disorders of the victims. Broadly speaking, this research can provide new ideas related to appropriate psychological and medical treatment for female sexual violence victims. In practical terms, this research is expected to broaden readers' insights about sexual violence in Indonesia and eliminate the stigma of society towards female sexual violence victims. In addition, this research is expected to be a reference in the field of health psychology and the medical field in providing the best treatment for victims.

\subsection{Paper Structure}

Furthermore, this article will explain the connecting theory in section 2. In section 3, the data collection methods and the screening stage will be explained further. Section 4 will discuss the results of the analysis of the studies that have been collected. Then section 5 concludes with the conclusion of the overall results. 


\section{BACKGROUND}

\subsection{Mediating Theory}

The main theory that can explain the relationship between somatic symptoms in young adult female sexual violence victims is the mind-body relationship theory. MallorquíBagué et al. [29] proposed a new perspective on mind-body relationships by stating that the physical expression of one's emotions and cognition to emotional expression is important in the emergence of anxiety and somatic symptoms. According to them, the individual's interpretation of something constitutes the formation of perception and interpretation of bodily sensations. Broadly speaking, these studies suggest that negative interpretations of perceived physical experiences can produce anxiety. These negative emotional states can elevate the physiological impact on the individual. Attribution and misinterpretation of negative emotions is a major factor in developing anxiety, including the appearance of panic and somatic symptoms related to anxiety. In addition to the concept of interoception, the key to cognitive theory of mind-body relationship is the integration of bottom-up and top-down processes, where information is not only processed from body to brain but also from brain to body which can cause certain bodily sensations or somatic symptoms [29].

\section{METHODS}

The inclusion criteria were established by researchers to facilitate the screening process. The inclusion criteria established for this study is that the data is in the form of academic, state, or professional studies with extensive data, the results of the study can describe a positive relationship between the description of somatic symptom manifestations and trauma of sexual violence, and finally the research must have a DOI and the journal is either Q1 or Q2. Furthermore, the exclusion criteria established were studies with insignificant results, studies with small amount of data so that they could not be generalized, studies that were not registered in the international journal database, studies originating from within the country, and studies that were not in English. The websites and databases that are the source of the research's data search are ScienceDirect by Elsevier, Taylor \& Francis Online, and PubMed. The data search began by determining the article search keywords. The search keywords in this systematic review study are a combination of "somatic symptoms" or "somatization", "sexual violence" or "sexual assault" or "sexual abuse" or "woman victims of sexual assault" or "sexually abused woman". After determining the keywords, the researcher determined the desired publication year, starting from 2015 to 2020 . Then, the authors continued with the desired type of publication, namely journals, theses or dissertations, and books. 272 data were successfully collected in a database search and continued with abstract screening and full-text screening. The researchers acquired eight studies that fits the criteria and will be analyzed. The limited year is the reason the researchers can only collect 8 relevant studies.

\subsection{Screening Studies}

This article used PRISMA 2009 Flow Diagram to select studies for this systematic review research.

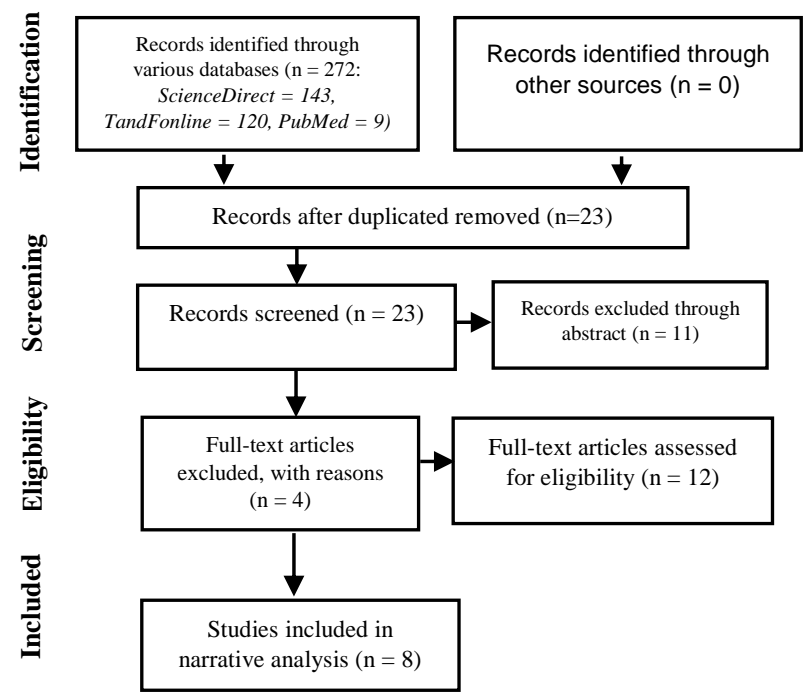

Figure 1 Research Scheme

\section{FINDINGS AND DISCUSSIONS}

There are 8 selected studies that fit the criteria for this systematic review research. First, a study by Littleton [26] The study was conducted on 407 pregnant women with a mean age of 27 years, the majority of participants were African-American and Caucasian women and the majority of pregnancies were unplanned. Littleton examined the appearance of somatic symptoms in pregnant women who had a history of sexual violence with depression as a mediator. The majority of participants come from the lowermiddle income group and only have graduated from high school. Most of the participants were not married and reported that their pregnancy was unplanned and they had one or more children at home. In the study, it was shown that African-American women experience less sexual violence. Littleton stated that pregnancy is a stressor that significantly contributes to the emergence of depression which later manifests with somatic symptoms. Apart from the pregnancy itself, socioeconomic status and already raising children can promote depression.

Research by Gottfried et al. [15] focuses on how MMPI-2$\mathrm{RF}$ is able to measure the impact of physical and sexual violence trauma on participants as well as the posttraumatic scale (PSA). Analysis on 212 female prisoners proved that participants who reported post-traumatic symptoms of sexual and physical violence also had high scores on several MMPI-2-RF items, especially on problems with antisocial behavior, sadness, anxiety, emotional disturbances, feeling of uselessness, stress, internalizing dysfunction, disaffiliation, and indigestion. Post-traumatic symptoms are also reported to be closely related to the appearance of somatic symptoms other than digestive disorders such as 
neurological complaints and cognitive disorders. Participants in this study reported that the perpetrator of sexual violence was a close relative, even biological father, or stepfather. A history of physical and sexual violence experienced has an impact on the increase in deviant behavior and criminal behavior in the participants.

The next study is a study by Granot et al. [16] which aims to look at the description of trauma, attachment style, and somatization felt by two groups of participants, which are women with dyspareunia disorder and women with a history of being victims of sexual violence. The results show that the insecure attachment style accompanied by high levels of anxiety in women with a history of sexual violence is a supporting factor for the emergence of somatic symptoms. According to this research, the number of somatic symptoms that appear is a way for women victims of sexual violence to show the difficulties they face and how they communicate their concerns. The average participant reported experiencing sexual violence at the age of 9 years. Education level and employment status did not have a significant effect on the participants from both groups.

Research in Asia by Nair, Satyanarayana, and Desai [32] focused on the prevalence of intimate partner violence (IPV) and the clinical correlation of IPV with the onset of severe mental disorders and the presence of somatic symptoms. As many as $18.2 \%$ of participants who reported experiencing sexual violence explained that sexual violence experienced was in the form of coercion to have intercourse against the victim's wishes, when the victim was menstruating, and without using contraceptives. Nair, Satyanarayana, and Desai reported that $58 \%$ of the participants were diagnosed with psychosis and $42 \%$ had bipolar disorder, $22 \%$ of participants had IPV during their lifetime and $20 \%$ reported IPV in the last 1 year. The interview results showed indications of depression, suicidal thoughts, feelings of grandeur or grandiose, and suspicion. Then, the results showed that women with a history of IPV reported more frequent physical health problems and somatic symptoms such as pain, sensory somatic symptoms, somatic symptoms related to biological function, and several other somatic symptoms. This study also explained that $88 \%$ of the victims had received formal education and $92 \%$ of the victims were housewives. On average, the perpetrators were husbands or working spouses with an average age of 40 years. The partners of victims reported having alcohol dependence syndrome, nicotine dependence syndrome, or alcohol and nicotine dependence syndrome. Research by Peles et al. [34] attempted to examine the relationship between sexual violence experienced by female participants with chronic pain that emerged. Participants in this study were divided into two groups, namely 76 female patients with methadone maintenance treatment (MMT) and 25 female patients from the Sexual Abuse Treatment Center (SATC). SATC patients on average have a higher level of education than MMT patients. The results showed chronic pain was felt by $60.3 \%$ or as many as 41 women out of 68 MMT women who had a history of sexual violence, and 21 others $(30.9 \%)$ experienced severe chronic pain. Among the 68 MMT female patients with a history of sexual violence, 22 of them experienced sexual-related PTSD, 13 of them had cPTSD, 45 of them had obsessive compulsive disorder (OCD), and 8 of them had high dissociation scores. The area of the body most frequently complained of pain in the SATC group of women was the head, while among MMT patients the area of the body that experienced pain was the legs.

The severity of pain and the number of areas correlated with the severity of the dissociation, cPTSD and PTSD. On a different background, research by Rometsch et al. (2020) examined pain, somatic symptoms, and subjective concepts of disease in female survivors or refugees who have experienced physical and sexual violence by the Islamic State (IS). Participants were 116 people with an average age of 32 years and had been a hostage in IS for 6 months. The results of the overall study showed that most of the participants felt that their lives were controlled by someone other than themselves due to trauma. This feeling was significantly correlated with participants who experienced somatic symptoms. Research by Rometsch et al. [36] reported that the somatic symptoms most often experienced by some participants were pain, choking, and movement disorders. There were 25 participants who reported other somatic symptoms such as back pain, headache, internal organ pain, difficulty in movement, difficulty in moving feet, kidney and eye problems, hair loss, anger, and fear of oneself.

The next study was a study conducted by Scioli-Salter, et al. [39]. Scioli-Salter, et al. which examined depression and dissociation as predictors of the onset of somatic symptoms in female rape victims with PTSD. There were 132 women who were among the victims of rape (experienced at least one incident of rape, CSA, physical violence, marital rape, incest) with an average age of 32 years consisting of $72.7 \%$ Caucasian, 22.7\% African-American, 1.5\% Hispanic, $0.8 \%$ Asian, $0.8 \%$ American-Indian, and $1.5 \%$ participants of other ethnicities. As many as $80 \%$ of participants were never married or divorced. The results showed that as many as 81 participants with CSA and a history of physical violence, the severity of PTSD affected the appearance of somatic symptoms (by 11\%). Depression and dissociation accounted for $13.6 \%$ and $5 \%$ of the appearance of somatic symptoms, namely physical pain. Overall, participants' scores on BDI and TSI-Dissociation were significant predictors of somatic symptoms.

Finally, Siltala, Kuusinen-Laukkala, and Holma [40] conducted a study comparing mental health and somatic diagnoses in female victims of family violence. Participants were patients in downtown Finnish hospitals and the average age was 32 years. All patients experiencing sexual violence $(n=32)$ were women and $90.1 \%$ of female patients were victims of family violence $(n=111)$. It should be noted that half of the total participants were women. The results showed that female victims of sexual violence and family violence significantly experienced more somatic symptoms such as respiratory problems and genital and urinary disorders. In addition, participants who experienced sexual violence were more likely to experience mood disorders, neurotic disorders, and somatic sensations of a neurological nature. According to Siltala, Kuusinen-Laukkala, and 
Holma interpersonal violence experienced by women is not just a personal problem but a sociopolitical issue.

\section{CONCLUSIONS AND LIMITATIONS}

The results of the 8 studies that have been analyzed show that the psychological disorders experienced by female sexual violence victims can cause various somatic symptoms. All selected studies show results that are consistent with previous research, that the group most prone to experiencing psychological disorders due to trauma are women $[1,9,18]$ especially sexual violence trauma $[31,10$, 40]. The most common somatic symptoms are physical pain, headaches, respiratory problems, and impaired biological or internal organ function. In depth, the majority of selected studies indicate that perpetrators of sexual violence come from their families or are partners. The socioeconomic status of the victim did not have a significant effect, however the mental condition of the perpetrator was the main cause of sexual violence. The different results shown by the research of Rometsch et al. [36] states that being a victim of oppression, war, or hostage can exacerbate somatic symptoms that appear. One of the limitations in this study is the years selected, which was concluded from 2015 until late 2020. By the time this research has been constructed, similar researches are limited, and rarely conducted.

\section{ACKNOWLEDGMENT}

This work was supported by Faculty of Psychology, Universitas Tarumanagara.

\section{REFERENCES}

[1] Acierno, R., Lawyer, S. R., Rheingold, A., Kilpatrick, D. G., Resnick, H. S., \& Saunders, B. E. (2007). Current psychopathology in previously assaulted older adults. Journal of Interpersonal Violence. https://doi.org/10. $1177 / 0886260506295369$

[2] Adams, J., Mrug, S., \& Knight, D. C. (2018). Characteristics of child physical and sexual abuse as predictors of psychopathology. Child Abuse and Neglect. https://doi.org/10.1016/j.chiabu.2018.09.019

[3] American Psychiatric Association. (2013). DSM-5 Diagnostic Classification (h. 309-314). Diagnostic and Statistical Manual of Mental Disorders. https://doi. org/10.1176/appi.books.9780890425596.x00diagnostic classification

[4] Bae, S. M., Kang, J. M., Chang, H. Y., Han, W., \& Lee, S. H. (2018). PTSD correlates with somatization in sexually abused children: Type of abuse moderates the effect of PTSD on somatization. PLoS ONE. https:// doi.org/10.1371/journal.pone.0199138

[5] Bloom, S. (2005). Understanding the Impact of Sexual Assault: The Nature of Traumatic Experience. MIS Quarterly.

6] Bonvanie, I. J., van Gils, A., Janssens, K. A. M., \& Rosmalen, J. G. M. (2015). Sexual abuse predicts functional somatic symptoms: An adolescent population study. Child Abuse and Neglect. https://doi.org/10.1016/ j.chiabu.2015.06.001

[7] Breuer, J., \& Freud, S. (1995). Studies on Hysteria. The Standard Edition of the Complete Psychological Works of Sigmund Freud (Vol. 2). London: Hogarth Press.

[8] Carey, K. B., Norris, A. L., Durney, S. E., Shepardson, R. L., \& Carey, M. P. (2018). Mental health consequences of sexual assault among first-year college women. Journal of American College Health. https:// doi.org/10.1080/07448481.2018.1431915

[9] Carmassi, C., Dell'Oste, V., Barberi, F. M. Pedrinelli, V., Cordone, A., Cappelli, A., ... Dell'Osso, L. (2020). Do somatic symptoms relate to PTSD and gender after earthquake exposure? A cross-sectional study on young adult survivors in Italy. CNS Spectrums. https://doi.org/10.1017/S1092852920000097

[10] Chang, E. C., Lee, J., Morris, L. E., Lucas, A. G., Chang, O. D., \& Hirsch, J. K. (2017). A Preliminary Examination of Negative Life Events and Sexual Assault Victimization as Predictors of Psychological Functioning in Female College Students: Does One Matter More Than the Other? Journal of Interpersonal Violence. https://doi.org/10.1177/0886260517719901

[11] Ciocca, G., Limoncin, E., Di Tommaso, S., Gravina, G. L., Di Sante, S., Carosa, E., ... Jannini, E. A. (2013). Alexithymia and vaginismus: A preliminary correlation perspective. International Journal of Impotence Research, 25, 113-116. https://doi.org/10.1038/ijir. 2013.5

[12] Erikson, E. (1968). Idemtity: Youth and crisis. In New York, NY: WW. https://doi.org/10.1002/yd.29

[13] Garcia-Moreno, C., Jansen, H. a F. M., Ellsberg, M., Heise, L., \& Watts, C. H. (2005). WHO Multi-Country Study on Women's Health and Domestic Violence Against Women: Initital Results on Prevalence, Health Outcomes and Women's Resposnes. Genetics. Geneva: World Health Organization. 
[14] Gibson, L. E., Cooper, S., Reeves, L. E., Anglin, D. M., \& Ellman, L. M. (2017). The association between traumatic life events and psychological symptoms from a conservative, transdiagnostic perspective. Psychiatry Research. https://doi.org/10.1016/j.psychres.2017.02. 047

[15] Gottfried, E. D., Anestis, J. C., Dillon, K. H., \& Carbonell, J. L. (2016). The Associations Between the Minnesota Multiphasic Personality Inventory-2Restructured Form and Self-Reported Physical and Sexual Abuse and Posttraumatic Symptoms in a Sample of Incarcerated Women. International Journal of Forensic Mental Health, 15(4), 323-332. https://doi. org/10.1080/14999013.2016.1228088

[16] Granot, M., Yovell, Y., Somer, E., Beny, A., Sadger, R., Uliel-Mirkin, R., \& Zisman-Ilani, Y. (2018). Trauma, attachment style, and somatization: A study of Women with Dyspareunia and Women Survivors of Sexual Abuse. BMC Women's Health, 18(29), 1-6. https://doi.org/10.1186/s12905-018-0523-2

[17] Gray, M.J., Litz, B.T., Hsu, J.L., Lombardo, T.W., 2004. Psychometric properties of the life events checklist. Assessment 11 (4), 330-341. http://dx.doi. org/10.1177/ 1073191104269954.

[18] Haug, T. T., Mykletun, A., \& Dahl, A. A. (2004). The association between anxiety, depression, and somatic symptoms in a large population: The HUNT-II study. Psychosomatic Medicine. https://doi.org/10.1097/ 01.psy.0000145823.85658.0c

[19] Janet, P. (1929). The Major Symptoms of Hysteria (2nd ed.). New York: The MacMillan Company.

[20] Jumper, S. A. (1995). A meta-analysis of the relationship of child sexual abuse to adult psychological adjustment. Child Abuse and Neglect. https://doi.org/ 10.1016/0145-2134(95)00029-8

[21] Kessler, R. (2003). Epidemiology of women and depression. Journal of Affective Disorders, 74(1), 513. DOI:10.1016/s0165-0327(02)00426-3

[22] King, L. A. (University of M. (2010). The Science of Psychology: an Appreciative View (4th ed., h. 12, 502-503). McGraw-Hill. https://doi.org/10.2753/ RPO1061-0405500404

[23] KOMNAS Perempuan. (2020). CATATAN KEKERASAN TERHADAP PEREMPUAN TAHUN 2018-2019. Catatan Tahunan Tentang Kekerasan Terhadap Perempuan.
[24] Koo, K. H., Nguyen, H. V., Gilmore, A. K., Blayney, J. A., \& Kaysen, D. L. (2014). Posttraumatic cognitions, somatization, and PTSD severity among Asian American and White college women with sexual trauma histories. Psychological Trauma: Theory, Research, Practice, and Policy. https://doi.org/10.1037/ a0033830

[25] Kuehner, C. (2017). Why is depression more common among women than among men? The Lancet Psychiatry, 4(2), 146-158. DOI:10.1016/s2215-0366 (16)30263-2

[26] Littleton, H. (2015). Sexual Victimization and Somatic Complaints in Pregnancy: Examination of Depression as a Mediator. Women's Health Issues, 25(6), 696-702. https://doi.org/10.1016/j.whi.2015.06. 013

[27] Luce, H., Schrager, S., \& Gilchrist, V. (2010). Sexual assault of women. American Family Physician, 81(4), 489-495. https://doi.org/10.1177/ 1077801203255680

[28] Maes, M., Mylle, J., Delmeire, L., \& Janca, A. (2001). Pre- and post-disaster negative life events in relation to the incidence and severity of post-traumatic stress disorder. Psychiatry Research, 105(1-2), 1-12. https://doi.org/10.1016/S0165-1781(01)00325-0

[29] Mallorquí-Bagué, N., Bulbena, A., Pailhez, G., Garfinkel, S. N., \& Critchley, H. D. (2016). Mind-Body Interactions in Anxiety and Somatic Symptoms. Harvard Review of Psychiatry, 24(1), 53-60. DOI: 10.1097/ hrp.0000000000000085

[30] Mallorquí-Bagué, N., Bulbena, A., Pailhez, G., Garfinkel, S. N., \& Critchley, H. D. (2016). Mind-Body Interactions in Anxiety and Somatic Symptoms. Harvard Review of Psychiatry, 24(1), 53-60. https://doi.org/10. 1097/HRP.0000000000000085

[31] Molnar, B. E., Buka, S. L., \& Kessler, R. C. (2001). Child sexual abuse and subsequent psychopathology: Results from the national comorbidity survey. American Journal of Public Health. https://doi.org/10.2105/AJPH. 91.5.753

[32] Nair, S., A Satyanarayana, V., \& Desai, G. (2020). Prevalence and clinical correlates of intimate partner violence (IPV) in women with severe mental illness (SMI). Asian Journal of Psychiatry, 52, 102131. https:// doi.org/10.1016/j.ajp.2020.102131

[33] Papalia, D. E., \& Martorell, G. (2016). Experience Human Development (13th ed., h. 385-394). McGraw Hill Education. https://doi.org/10.1093/brain/awn110 
[34] Peles, E., Seligman, Z., Bloch, M., Potik, D., Sason, A., Schreiber, S., \& Adelson, M. (2016). Sexual Abuse and its Relation to Chronic Pain among Women from a Methadone Maintenance Clinic versus a Sexual Abuse Treatment Center. Journal of Psychoactive Drugs, 48(4), 279-287. https://doi.org/10.1080/02791072.2016. 1205763

[35] Roenneberg, C., Sattel, H., Schaefert, R., Henningsen, P., \& Hausteiner-Wiehle, C. (2019). Functional Somatic Symptoms. Deutsches Arzteblatt international, 116(33-34), 553-560. https://doi.org/10. 3238/arztebl.2019.0553

[36] Rometsch, C., Denkinger, J. K., Engelhardt, M., Windthorst, P., Graf, J., Gibbons, N., ... Junne, F. (2020). Pain, somatic complaints, and subjective concepts of illness in traumatized female refugees who experienced extreme violence by the "Islamic State" (IS). Journal of Psychosomatic Research, 130, 109931. https://doi.org/10.1016/j.jpsychores.2020.109931

[37] Samelius, L., Wijma, B., Wingren, G., \& Wijma, K. (2007). Somatization in Abused Women. Journal of Women's Health, 16(6), 909-918. DOI: 10.1089/jwh. 2006.0103

[38] Saunders, B. E., Villeponteaux, L. A., Lipovsky, J. A., Kilpatrick, D. G., \& Veronen, L. J. (1992). Child Sexual Assault as a Risk Factor for Mental Disorders Among Women: A Community Survey. Journal of Interpersonal Violence. https://doi.org/10.1177/ 088626092007002005

[39] Scioli-Salter, E. R., Johnides, B. D., Mitchell, K. S., Smith, B. N., Resick, P. A., \& Rasmusson, A. M. (2016). Depression and Dissociation as Predictors of Physical Health Symptoms among Female Rape Survivors with Posttraumatic Stress Disorder. Psychological Trauma: Theory, Research, Practice, and Policy, 8(5), 585-591. https://doi.org/10.1037/tra0000135

[40] Siltala, H. P., Kuusinen-Laukkala, A., \& Holma, J. M. (2020). Victims of family violence identified in emergency care: Comparisons of mental health and somatic diagnoses with other victims of interpersonal violence by a retrospective chart review. Preventive Medicine Reports, 19, 101136. https://doi.org/10.1016/j. pmedr.2020.101136

[41] Siqveland, J., Ruud, T., \& Hauff, E. (2017). Posttraumatic stress disorder moderates the relationship between trauma exposure and chronic pain. European Journal of Psychotraumatology. https://doi.org/10.1080/ 20008198.2017.1375337
[42] Stein, M. B., Lang, A. J., Laffaye, C., Satz, L. E., Lenox, R. J., \& Dresselhaus, T. R. (2004). Relationship of sexual assault history to somatic symptoms and health anxiety in women. General Hospital Psychiatry. https://doi.org/10.1016/j.genhosppsych.2003.11.003

[43] Thompson, N. J., Potter, J. S., Sanderson, C. A., \& Maibach, E. W. (1997). The relationship of sexual abuse and HIV risk behaviors among heterosexual adult female STD patients. Child Abuse \& Neglect, 21(2), 149-156. DOI:10.1016/s0145-2134(96)00140-8

[44] Thurston, R. C., Chang, Y., Matthews, K. A., Von Känel, R., \& Koenen, K. (2019). Association of Sexual Harassment and Sexual Assault with Midlife Women's Mental and Physical Health. JAMA Internal Medicine. https://doi.org/10.1001/jamainternmed.2018.4886

[45] Ulirsch, J. C., Ballina, L. E., Soward, A. C., Rossi, C., Hauda, W., Holbrook, D., McLean, S. A. (2013). Pain and somatic symptoms are sequelae of sexual assault: Results of a prospective longitudinal study. European Journal of Pain (United Kingdom). https:// doi.org/10.1002/j.1532-2149.2013.00395.x 